Brit. J. vener. Dis. (1965), 41, 214.

\title{
MEDICAL SOCIAL WORKERS AND THE PROBLEMS OF VENEREAL DISEASES*
}

\author{
BY \\ MRS. R. K. T. STUBBS \\ Medical Social Worker, Department of Venereal Diseases, St. Thomas's Hospital, London
}

I am often asked what working in a Venereal Diseases Clinic is like, and what problems one meets. The answer depends partly on the particular clinic; although certain problems are universal, the patients vary greatly from place to place. I was made aware of this when I came to my present job after working as a locum for 6 months in the St. Bartholomew's clinic in which Miss Bird now works and about which she will tell you presently. That clinic was small, the majority of the patients were English and intelligent, and the atmosphere was very friendly. The change to my present job produced surprises initially. The male clinic was bombed in the war and the present makeshift department is tucked away in the basement. An entire new hospital is being built in stages but the clinic is unlikely to move for 10 years. Meanwhile every effort is made to make the existing department more attractive with fresh paint, flowers, pictures, and magazines. There are eleven doctors working on a sessional basis, nurses, male and female, working in shifts, laboratory staff, receptionists, and secretaries. There are large numbers of patients, many of them coloured imigrants. The clinic at first had seemed rather inhuman and factory-like, with the patients starting on a conveyor belt and emerging, if they stayed the course, 3 months later. First impressions can be very wrong and I soon found that, in spite of the pressure of work, all the patients were treated very much as individuals.

What could one medical social worker do amongst all this! Who would be referred to me when nearly every patient attending the clinic had a social problem? I soon collected several elderly tabetic patients of both sexes, with all the problems of the chronically disabled. I saw teenagers, homosexuals unable to accept their homosexuality, people with other sexual deviations, unmarried mothers, students from all over the world who were lonely in London,

*Paper read at a meeting of the MSSVD on January 29, 1965. and West Indians with the problems of first-generation immigrants. So many of the patients were West Indians that I gradually became able to tell a Barbadian from a Jamaican on sight. I was naturally concerned for all these patients, but what worried me most was the small stream of desperately unhappy and upset wives. This problem had been less pressing in the smaller clinic where the sexes were not segregated, where the same doctor saw the husband and wife, and where one could easily talk to them together.

The plight of two particular women finally persuaded me to try and do something about the problem of wives attending the clinic at the request of their husbands. The first was a most attractive young woman with auburn hair who was crying so hysterically that the doctor could not even take a history let alone examine her. When she was calmer she told me that her husband had rushed home, dragged her and the two children out of the house and into the car, and poured out to her on the way to the clinic that he had gonorrhoea and had probably given it to her and the children. He was so agitated that he had not allowed her to turn off the lunch, which was cooking, or to stop the semi-automatic washing machine. The thought of a stream of detergent over the floor, burnt saucepans, and the entire family infected with venereal disease presented a devastating prospect. I sent the husband home to see to the domestic matters, and the wife, who turned out to be very sensible once she had got over the shock, cheered up. This was a good marriage and when the couple was discharged it may have been strengthened rather than weakened by what they had been through together, despite this unfortunate start.

In the second case the husband had driven down to his home on the borders of London and Kent, and packed his wife and daughter in the car without letting the wife change out of her working clothes. 
He then drove as fast as he could to London and, as he approached the hospital, blurted out that he had had intercourse with another girl while away with a golfing team and had caught gonorrhoea. He then almost pushed her into the clinic, and she also was hysterical when interviewed. This marriage had not been particularly successful and, although the couple had not separated when they were discharged from the clinic, this episode had caused further damage.

The husbands who were asked to bring their wives to the clinic were not at this stage being referred to me because they were not considered to have a particular problem, but I decided to find out the methods by which wives were brought to the clinic. I discovered that, when tests had been completed, a diagnosis made, and treatment given, the husband was given a contact slip for his wife. In the smaller clinic this had been the responsibility of the doctors who discussed with each patient how this should be done, but in the larger clinic, owing to the pressure of work, it was delegated to the male nurses.

Discussion with the Director of the clinic showed that the medical and nursing staff had felt concern for some time about these patients, and one of the doctors working in the department was given a research grant by the hospital to investigate the emotional and marital disturbance which might result from the infection of one partner with a sexually-transmitted disease. Thereafter, to assist this investigation, which was entrusted to Dr John Seale, I was asked to see every husband who was requested to bring his wife to the clinic, to see the wife on arrival, and to make a detailed social assessment of each patient. Immigrants were excluded from this study because they were considered to have a different cultural background and a different attitude to their marital problems. During a period of about a year I saw 87 couples. The full statistics of this study will shortly be published by Dr Seale, who has already given the Society a preliminary report at the Annual General Meeting in Dublin on May 30, 1964, and I propose to outline here some of the social and emotional aspects of this problem which were brought out by the study.

The husbands were not, in most cases, highly promiscuous. Most of them had had sexual intercourse with women other than their present wives before marriage, but for many of them the occasion on which they acquired the venereal infection had been the only episode of extra-marital sexual intercourse. Whereas unskilled workers form a big percentage of all patients attending the clinic, most of the husbands who brought along their wives were skilled workers or professional men. Quite a number had jobs which took them away from home a good deal-long-distance lorry drivers, airline pilots, or commercial travellers.

The husbands who had only once had extramarital intercourse were the most distressed. It was necessary to win their confidence if they were to unburden themselves of all the guilt, misery, and fear which they felt in having involved a much-loved wife, and in having perhaps done irreparable harm to the marriage. When the man had calmed down we could discuss how his wife could be brought to the clinic with the least possible distress to her. Since few husbands feel able to tell their wives the truth it is important that what they do say should be something with which the medical staff can concur, such as, in the case of non-gonococcal urethritis, that they had "picked up an infection which occurs sometimes in married couples". It is important for a husband whose job takes him away from home to realize that, if his wife stops trusting him, her peace of mind may go for ever and she may suffer quite unjustifiable anxiety which may ruin the marriage.

For his wife's sake the husband must be calm and wait for a suitable moment to tell her of his visit to the hospital and of her need to attend. Her visit should be planned and she should come at a time convenient to her when the clinic is not busy, though this is difficult with no appointment system. I persuaded each husband to accompany his wife on the first visit to the clinic and after being introduced I talked with them. Unfortunately, we have no special waiting room for husbands and wives, but we used a bench in the grounds in the summer and a bench outside the laboratory upstairs in the winter. If the wife was nervous I warned the doctors and nurses. If the women's waiting room was crowded I let the wife wait with me in my office, thereby avoiding giggling teenagers discussing their boyfriends and last night's party. It was impossible for all the wives to be seen initially by Dr Seale but this was done wherever possible.

In most cases the wife was infected by the husband, but in about 10 per cent. of the couples the wife had introduced the infection into the family. The majority of the wives had had no extra-marital sexual intercourse, and most of those who had had premarital intercourse had had it with their future husbands only. All the women who were asked to bring their daughters to the clinic were distressed, and this was increased if they had not understood the nature of the examination their daughters were going to have.

Many of the wives whose husbands had nongonococcal urethritis were as disturbed emotionally 
as those who knew that their husbands had gonorrhoea. Although all those who had, or who were contacts of, non-gonococcal urethritis were told what was wrong, most of them did not understand the explanation. When the disease was diagnosed the male nurses gave the man a card to read about non-gonococcal urethritis, but many anxious patients did not take in a word or remembered only the more frightening parts of the explanation. When they came to my office I asked if they knew what was wrong and many said they had no idea, would I please tell them! Small wonder if they could not explain to their wives why they had to attend. Some couples in which the husband had non-gonococcal urethritis had been attending the clinic for several months and still did not know what was wrong, but believed they had a particularly intractable form of venereal disease. When the urethritis relapsed, as it often did, some thought it would never clear up. Young married couples sharing a double bed got edgy and difficult after refraining from intercourse for months on end, according to instructions. In order to help these patients it is now proposed to give the husbands a revised leaflet about nongonococcal urethritis which they can take away and also show to their wives, but no leaflet, however clear, is as good as an explanation from the doctor, and I sometimes find it necessary to ask the medical staff to see the patients again to clear up points which are worrying them. For example, a husband who had gonorrhoea read one pamphlet which stated that gonorrhoea and syphilis could only be picked up through sexual intercourse, and was very reasonably puzzled at being asked to bring his 2-year-old daughter to the clinic.

The social backgrounds of most of the couples were satisfactory, with little evidence of real financial difficulty or of bad housing. Sexual difficulties were severe in a small percentage only. Fear of pregnancy and unsatisfactory methods of birth control made a few of the wives try to avoid intercourse. A few of the older women never had pleasure from intercourse and had never reached a climax. One or two felt sex was disgusting and, of course, a visit to the clinic only confirmed this opinion.
There is a real risk that a married couple attending a clinic for venereal diseases may come to feel that intercourse is shameful, thereby undermining one of the most important aspects of marriage.

Most wives felt that the clinic was much nicer than they had expected, but the public image of a clinic for venereal diseases is still so deplorable that patients seem to expect to be hurt, humiliated, and preached at. I believe that the traditional atmosphere of disgrace and secrecy which surrounded the clinic troubled them, and when they got inside, many felt humiliated by being called by a number instead of by name, even when they understood that it was for their own protection. As one wife said, "I have done nothing disgraceful, I want to stand up in the clinic and shout, my name is Mrs. Jonesplease call me by it". Like the old buildings, much of this secrecy is a heritage from the past, which I regard as unnecessary nowadays when most of the patients do not have a venereal disease as legally defined. In our clinic, since January 1 the patient's name has been put on the medical notes so that the doctors and nurses can use it and, though it is too soon to judge, this seems to be much preferred. The new clinic will be in the general out-patients area and will be, I hope, in the minds of the patients "just another department".

After this investigation had been going on for several months and a pattern of management put into operation, the stream of very distressed wives had "dried up". This proves, I believe, that wives can be brought to a large and busy clinic for venereal diseases without great emotional distress or serious damage to the marriage, provided that everyone working there is aware of the problems and treats the patients sympathetically.

I am deeply indebted to Dr C. S. Nicol, Director of the Department, and to Dr John Seale for their invaluable assistance in the preparation of this paper. I should also like to express my gratitude to the rest of the medical and nursing staff for their help in this study; to Miss A. B. Read, head of the Social Service Department, for her advice and encouragement; and to Miss P. Howell for secretarial help. 